\title{
IL-1 $\beta$ Regulates FHL2 and Other Cytoskeleton-Related Genes in Human Chondrocytes
}

\author{
Helga Joos, ${ }_{1}^{1}$ Wolfgang Albrecht, ${ }^{2}$ Stefan Laufer, ${ }^{3}$ Heiko Reichel, ${ }^{4}$ and Rolf E Brenner ${ }^{1}$
}

${ }^{1}$ Division for Biochemistry of Joint and Connective Tissue Diseases, Department of Orthopedics, University of Ulm, Ulm, Germany; ${ }^{2}$ ratiopharm group, Department of Drug Research, Ulm, Germany; ${ }^{3}$ Institute of Pharmacy, Department of Pharmaceutical and Medicinal Chemistry, Eberhard-Karls University Tübingen, Tübingen, Germany; ${ }^{4}$ Department of Orthopedics, University of Ulm, Ulm, Germany

\begin{abstract}
In osteoarthritis (OA), cartilage destruction is associated not only with an imbalance of anabolic and catabolic processes but also with alterations of the cytoskeletal organization in chondrocytes, although their pathogenetic origin is largely unknown so far. Therefore, we have studied possible effects of the proinflammatory cytokine IL-1 $\beta$ on components of the cytoskeleton in OA chondrocytes on gene expression level. Using a whole genome array, we found that IL-1 $\beta$ is involved in the regulation of many cytoskeleton-related genes. Apart from well-known cytoskeletal components, the expression and regulation of four genes coding for LIM proteins were shown. These four genes were previously undescribed in the chondrocyte context. Quantitative PCR


mitogen-activated protein kinase (MAPK) by SB203580 counteracted the influence of IL- $1 \beta$ on Fh/2 and Tubb expression, indicating partial involvement of this signaling pathway. Downregulation of the LIM-only protein FHL2 was confirmed additionally on the protein level. In agreement with these results, IL-1 $\beta$ induced changes in the morphology of chondrocytes, the organization of the cytoskeleton, and the cellular distribution of FHL2. We conclude that L-1 $\beta$ is involved in the regulation of various cytoskeletal components in human chondrocytes including the multifunctional protein FHL2. This might be relevant for the pathogenesis of OA.

Online address: http://www.molmed.org
\end{abstract}

doi: 10.2119/2007-00118.Joos

\section{INTRODUCTION}

Osteoarthritis (OA) is one of the most common joint diseases, severely restricting the mobility of affected patients. In $\mathrm{OA}$, the balance between degradation and synthesis of the extracellular matrix (ECM) of articular cartilage is disturbed. Mechanical stress or joint inflammation results in enhanced production of degrading enzymes mediated by specific cytokines (1). One relevant cytokine in this context is the pleiotropic factor IL-1 $\beta$, which is known to induce a set of cartilage-degrading enzymes like matrix metalloproteinases (MMPs) and a disin- tegrin and metalloproteinase with thrombospondin motif (ADAMTS) $(2,3)$ and to downregulate the synthesis of important matrix components such as collagen type II and aggrecan $(4,5)$. Therefore, IL-1 $\beta$ stimulation of chondrocytes is a model widely used to investigate molecular events related to the development and progression of OA (6).

Further pathogenetic aspects of OA comprise alterations in the phenotype and cytoskeleton of chondrocytes (7). A disturbed cellular distribution of main cytoskeletal components in OA cartilage has been described (8). However, the

Address correspondence and reprint requests to Rolf Brenner, Division for Biochemistry of Joint and Connective Tissue Diseases, Department of Orthopedics, University of UIm, Oberer Eselsberg 45, 89081 Ulm, Germany. Phone: 0049-73 1-500-63280; Fax: 0049-73 1-50063282; E-mail: rolf.brenner@uni-ulm.de. Submitted November 14, 2007; Accepted for publication January 14, 2008; Epub (www. molmed.org) ahead of print January 22, 2008.

underlying mechanisms are largely unknown. Several consequences of cytoskeletal changes in chondrocytes have been described so far. Beside an influence on viscoelastic properties (9), the cellular metabolism is affected (10). In particular, alterations in the cytoskeleton are known to modify nitric oxide(NO-) induced cell reactions (11) and give rise to lytic enzyme expression (12). IL-1 $\beta$ signaling partially involves focal adhesion complexes (FACs), as IL-1receptors are enriched at focal adhesion sites and the FAC-associated protein IRAK is required for IL-1-dependent ERK activation (13).

IL-1 $\beta$ controls mRNA-expression via different signaling pathways. A wellknown key enzyme in one of these pathways in chondrocytes is the p38 MAP kinase, which has been found to be involved in IL-1 $\beta$-induced gene regulation of several genes including aggrecan and NOS2A $(14,15)$. These findings make 
p38 MAPK an interesting pharmaceutical target in inflammatory joint diseases.

We have conducted a whole human genome oligo-microarray to investigate the possible influence of IL- $1 \beta$ and p38 MAPK-inhibition on articular human chondrocyte gene expression and have found a high number of affected genes involved in cytoskeletal organization. To verify the microarray results, Vim, Tubb, and a group of genes encoding LIM proteins (Fhl1, Fhl2, Lasp1, and Pdlim1) not described previously in chondrocytes were analyzed by quantitative PCR. LIM proteins contain zinc-binding, cysteinerich modules known as LIM domains. These conserved motifs mediate interactions with a variety of proteins in different cellular components (16). Several LIM proteins are associated with the actin cytoskeleton (17), as are those studied in this paper. The expression of FHL2 as the best studied member of the fourand-a-half-LIM-only protein family has been investigated further by Western blot. Finally, possible changes in the morphology of chondrocytes, the organization of their actin cytoskeleton, and FHL2 distribution induced by IL-1 $\beta$ have been analyzed.

\section{MATERIALS AND METHODS}

\section{Cartilage Samples}

Human osteoarthritic cartilage was obtained from donors undergoing total knee replacement due to osteoarthritis with informed consent of the patients according to the terms of the Ethics Committee of the University of Ulm. The age of the donors ranged from 58 to $72 \mathrm{y}$.

\section{Cell Culture}

Well-preserved cartilage from femoral condyles up to a Mankin score (18) of 7 was used for chondrocyte isolation. The cartilage was minced and digested 45 min with 9 U/mL Pronase (SigmaAldrich, Munich, Germany) and $14 \mathrm{~h}$ with $80 \mathrm{U} / \mathrm{mL}$ Collagenase (Sigma) in DMEM. After washing with DMEM and filtering through a $70 \mu \mathrm{m}$ cell strainer (BD Falcon, Heidelberg, Germany), cells were cultivated in complete medium consisting of 1:1 DMEM/Hams F12 supplemented with $10 \%$ fetal bovine serum, $0.5 \%$ penicillin/streptomycin, $0.5 \%$ L-glutamine and $10 \mu \mathrm{g} / \mathrm{mL}$ 2-phospho-Lascorbic acid trisodium salt (SigmaAldrich, Fluka, Seelze, Germany). After overnight adherence, the chondrocytes were frozen in complete medium containing 5\% dimethyl sulfoxide (DMSO) (Roth, Karlsruhe, Germany) and stored in liquid nitrogen. All chemicals were obtained from Biochrom, Berlin, Germany, unless indicated otherwise.

\section{Cell Stimulation and Treatment with p38 MAPK Inhibitor}

For microarray and quantitative PCR experiments, thawed cells were cultivated for 1 to 3 days at a density of $5 \times 10^{4}$ cells $/ \mathrm{cm}^{2}$ in complete medium and silenced for $24 \mathrm{~h}$ in serum-free medium (DMEM containing $0.5 \%$ penicillin/ streptomycin, $0.5 \%$ L-glutamine, $1 \%$ non essential amino acids 100-fold concentrate, $1 \mathrm{mM}$ Pyruvat, $0.1 \%$ SES1 Solution $\mathrm{A}$, and $0.1 \%$ freshly added SES1 Solution B; Biochrom). Cells were stimulated for the indicated time with $10 \mathrm{ng} / \mathrm{mL} \mathrm{rh}$ IL-1 $\beta$ (tebu-bio, Offenbach, Germany) in serum-free medium. Inhibitor-treated cells were preincubated for $15 \mathrm{~min}$ prior to stimulation and coincubated in parallel with $10 \mu \mathrm{M}$ SB203580 (ratiopharm, Ulm) with a final DMSO-concentration of $0.1 \%$ in the cultivation medium. For comparability, the same amount of DMSO was added to control cells. At the end of the stimulation period, cells were washed 2 times in sterile phosphate buffered saline (PBS) (PAA laboratories, Egelsbach, Germany) and lysed in $600 \mu \mathrm{l}$ lysis buffer RLT (Qiagen, Hilden, Germany) per $10^{6}$ cells. The overall cultivation time prior to cell lysis ranged from 7 to 9 days.

\section{Microarray Experiment}

To obtain enough RNA for the microarray experiment, cells of six different donors were pooled after thawing and split into three groups. One group served as control, one group was stimulated with IL-1 $\beta$, and one group was incubated with SB203580 and IL-1 $\beta$ as described above. The stimulation time was $24 \mathrm{~h}$. After cell lysis, a whole human genome oligo-microarray (Human Genome Oligo-Set-Version 2.0, Operon, Germany), representing 21,329 genes, was conducted at the Chip facility of Ulm according to Buchholz et al. (19). The experiment was performed three times with six different donors each. By using this experimental design with biological replication, we were able to assess biological variation despite the need to pool different donors (20).

\section{Gene Ontologies}

Genes that showed at least a two-fold regulation and a significance level of $P<$ 0.05 in the microarray analysis were assigned to cellular components with the fatiGO program $(21,22)$ using the level 5 filtering parameter. The affected cellular components were ranked according to the percentage of genes assigned to the respective component.

\section{mRNA-Isolation and CDNA-Synthesis}

For RNA-isolation from cultured cells, the RNeasy mini kit (Qiagen) was used according to the manufacturer's instructions. Briefly, the cell lysate was mixed $1: 1$ with $70 \%$ ethanol, loaded on a mini column, and, after several washing steps and DNase digestion, the RNA was eluted in $30 \mu \mathrm{l}$ of RNase free water. cDNA was synthesized with Omniscript RT (Qiagen) in accordance with the manufacturer's instructions using $12 \mu \mathrm{l}$ of RNA-solution.

\section{Polymerase Chain Reaction (PCR)}

Semiquantitative reverse transcriptase (RT) PCR was used to detect human Col2 (collagen type II), Acan (aggrecan), Comp (cartilage oligomeric matrix protein), and Gapdh (glyceraldehyde-3-phosphate dehydrogenase). Primers are given in Table 1. The PCR was performed using HotStarTaq Plus polymerase and buffer set (Qiagen) according to the manufacturer's instructions. Quantitative real-time PCR was used to detect human Fhl1, Fhl2, 
Table 1. Primers

Sequences of primers used for quantitative real-time-PCR and semiquantitative RT-PCR.

\begin{tabular}{|c|c|c|c|}
\hline & $\begin{array}{c}\text { GenBank } \\
\text { Accession No }\end{array}$ & $\begin{array}{c}\text { Forward } \\
5^{\prime}-3^{\prime}\end{array}$ & $\begin{array}{c}\text { Reverse } \\
5^{\prime}-3^{\prime}\end{array}$ \\
\hline \multicolumn{4}{|c|}{ Primer for real-time PCR } \\
\hline $\mathrm{FHL} 1$ & NM_001449 & CTGCGTGGATTGCTACAAGA & GTGCCAGGATTGTCCTTCAT \\
\hline $\mathrm{FHL} 2$ & NM_001450 & GGTACCCGCAAGATGGAGTA & TITGGGGATGAAACTCTTGG \\
\hline LASP1 & NM_006148 & TGCGCTACAAGGAGGAGTTT & TGATCTGGTCCTGGGTCTTC \\
\hline PDLIM1 & NM_020992 & AATGTGGCACTGGGATTGTT & GAAATGGCCCTTCTGTTTCA \\
\hline TUBB & NM_001069 & TGACTTGCAGCTGGAGAGAA & GTCTGAAGATCTGGCCGAAG \\
\hline VIM & NM_003380 & GAGAACTTTGCCGTTGAAGC & CTCAATGTCAAGGGCCATCT \\
\hline 18SrRNA & X03205 & CGCAGCTAGGAATAATGGAATAGG & CATGGCCTCAGTTCCGAAA \\
\hline \multicolumn{4}{|c|}{ Primer for RT-PCR } \\
\hline COLII & NM_03315 & CAGGGGTGAACGAGGITTC & CACGAGCACCAGCACTTCC \\
\hline ACAN & NM_001135 & CACTGTTACCGCCACTTCCC & GACATCGTTCCACTCGCCCT \\
\hline COMP & NM_000095 & AGCAGATGGAGCAAACGTATTG & TGGAAGACTTCACAGCCTTG \\
\hline GAPDH & NM_002046 & GAGTCCACTGGCGTCTTCAC & GGTGCTAAGCAGTTGGTGGT \\
\hline
\end{tabular}

Lasp1, Pdlim1, Tubb, and Vim in human articular chondrocytes. The primers (Table 1) were designed using Primer 3 software (23). To obtain quantifiable results for all genes, specific standard curves using sequence-specific control probes were performed in parallel to the analyses. Therefore, a gene-specific cDNA fragment was amplified for each gene, using the specified primers (Table 1), and purified by using the NucleoSpin Extract Kit (Macherey-Nagel, Düren, Germany). The sequences were cloned into the $\mathrm{PCR}$ 2.1 TOPO vector using the TOPO TA Cloning Kit (Invitrogen, Karlsruhe, Germany) and plasmids were extracted using the Qiafilter Plasmid Midi Kit (Qiagen). The purified plasmids were quantified by measuring the absorbance at $260 \mathrm{~nm}$ in a spectrophotometer (GE Healthcare, München, Germany) and the inserts of the plasmids were sequenced for confirmation of correct amplification products of the specific primers. Expression of the genes was detected with the AbiPrism 7000 system (Applera, Darmstadt, Germany). For all analyzed genes, the Invitrogen Platinum SYBR qPCR SuperMix UDG (Invitrogen) was used according to the manufacturer's instructions, except Vim, for which Power SYBR Green PCR Master Mix (Applied Biosystems) was utilized. 18SrRNA was used as endogenous control, the applied concen- tration of all primers was $1 \mu \mathrm{M}$. For the standard curve, 120, 1,200, 12,000, 120,000 and 1,200,000 molecules per assay were employed (all in triplicate). For real-time PCR, six different donors were analyzed.

\section{Cell Staining and Phase Contrast Microscopy}

For FHL2 and actin filament staining, chondrocytes were seeded onto Permanox slides (Nunc GmbH, KG, Wiesbaden) and cultivated for 2 to 3 days in complete medium. Afterward, cells were stimulated as described above and subsequently fixed in 3.7\% formaldehyde (Mallinckrodt Baker, Griesheim, Germany) in PBS for 5 min. Actin-labeling was performed with Phalloidin-FITC (Sigma-Aldrich, Fluka) for $40 \mathrm{~min}$ at room temperature protected from light. Bound FITC-conjugated Phalloidin was visualized by fluorescence microscopy (Zeiss Axioskop 2 mot plus, Oberkochen, Germany). For FHL2 staining, cells were incubated with anti-Fhl2 mAB clone F4B2 (dilution 1:2, gift of Victor Wixler, Muenster, Germany) for $1 \mathrm{~h}$ after permeabilization with $0.1 \%$ Triton X-100 (Merck, Darmstadt, Germany). Bound antibodies were visualized with DakoCytomation LSAB2 System-HRP (Dako, Hamburg, Germany). For morphological studies, cells were seeded in parallel on 12-well plates, treated equally and examined after the indicated time by inverse phase contrast microscopy.

\section{Western Blotting}

Cells of four different donors were pooled and stimulated as described, then trypsinized and lysed in SDS-buffer containing $12.5 \% 0.5 \mathrm{M}$ Tris (pH 6.8), $1 \%$ sodiumdodecyl sulfate, $15 \%$ glycerine, and $2.3 \mathrm{~g} / \mathrm{L}$ dithiothreitole. Equal protein amounts of the lysates were resolved by $12.5 \%$ SDS-PAGE. After electroblotting onto nitrocellulose membrane and over night blocking at $4^{\circ} \mathrm{C}$ in $5 \%$ nonfat dry milk, membranes were incubated with anti-Fhl2 mAB clone F4B2 (dilution 1:5) for $1 \mathrm{~h}$ at room temperature and developed with DakoCytomation LSAB2 System-HRP. Protein concentration of cell lysates was detected using Bradford reagent (Roti-Quant; Roth, Karlsruhe, Germany). Band densities of the immunoblots were quantified with the Geldoc XR System (Bio-Rad Laboratories $\mathrm{GmbH}$, Munich, Germany) and percent intensities were calculated referring to the corresponding control.

\section{STATISTICAL ANALYSIS}

For the microarray results, a Print-tip LOESS-normalization according to Buchholz et al. (19) and a moderated $t$-test (24), were performed at the chip facility 
of Ulm. For standardization of the gene expression levels determined by Taqmananalysis, mRNA-expression was normalized to 18SrRNA-expression. Differential regulation was determined by calculating the ratios of gene expression in different treatments. A two-tailed paired $t$-test of the calculated ratios was performed to evaluate significant differences from the relative control treatment as identical donors were always compared.

\section{RESULTS}

\section{Control of Cell Phenotype and Viability}

For the experiments, more than 40 donors provided OA cartilage with a macroscopically smooth surface and no severe osteoarthritic changes. The microarray experiment and real-time PCR experiments were performed with cells from different donors. A continuous check of collagen type II, aggrecan, and COMP (cartilage oligomeric matrix protein) expression during the experimental period confirmed a stable differentiation stage of the chondrocytes (Figure 1). Cell viability was specified by trypan blue staining and showed comparable results in the range of $80 \%$ to $90 \%$ with and without IL-1 $\beta$ stimulation.

\section{Microarray Experiment}

Chondrocyte-treatment with IL-1 $\beta$ induced numerous changes in the gene expression profile. The results of the microarray experiment confirmed many typical effects previously described in the literature. We observed that several ECM genes including Col2 and Col11 showed a downregulation by IL- $1 \beta$, whereas genes related to the inflammatory cascade, for example, Mmp1, Mmp13, Adamts10, Adamts3, Cox2, Nos2a, $I L-1 \beta, I l 6$, and Il8 were induced. Coincubation with SB203580 at least partially antagonized the IL-1 $\beta$ effect by downregulation of Mmp13, Cox2, and Nos $2 a$ in agreement with previous reports $(14,25,26)$. Examination of the affected genes involved categorization of

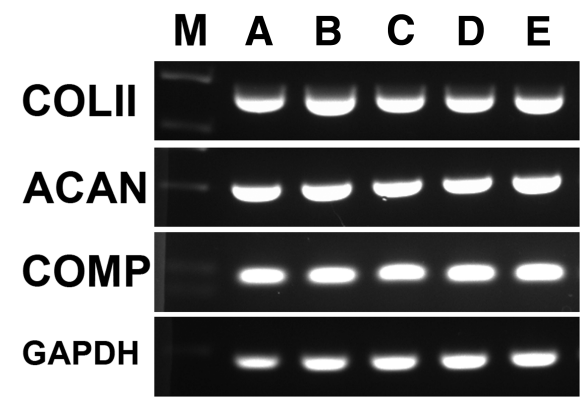

Figure 1. Preservation of the chondrogenic phenotype during the experiment. RT-PCR analysis for Collagen type II (COLII), Aggrecan (ACAN), and COMP is shown at different time points with GAPDH as housekeeping gene. M: Marker; A: directly after enzymatic preparation, passage 0 (PO); $\mathrm{B}: 1$ day of monolayer culture (PO) prior to cryoconservation; C: 3 days of cultivation after cryoconservation (P1); D: 5 days of cultivation after cryoconservation ( $\mathrm{Pl}$ ); E: 6 days of cultivation after cryoconservation (P1). The experiment was performed with three different donors and a representative example is shown.

differentially expressed transcripts to diverse cellular components. Classification according to Gene Ontology annotations showed that the majority of the IL-1 $\beta$ and SB203580-influenced genes were related to the cell membrane $(24 \%$ and $22 \%$ ), the nucleus (19\% and $21 \%$ ), and the plasma membrane (10\% both).

Though representing a rather small cellular component, the cytoskeleton $(6 \%$ and $7 \%$ ) was ranked fourth whereas other cell components were less represented. Table 2 and Table 3 present the list of IL-1 $\beta$ - and SB203580-regulated genes, respectively, involved in cytoskeletal context. We found many structural components of microfilaments, intermediate filaments, and microtubules, but also components of the FACs and integrins as well as factors that are involved in regulation and organization of the cytoskeleton. For further investigations by realtime PCR, a selection of regulated genes was made. The complete array data are deposited on ArrayExpress with the accession number E-MEXP-1434
Quantitative Gene Expression Analysis of Cytoskeletal Components

The cytoskeleton-related genes Fhll (four and a half LIM domains 1, GenBank:NM_001449), Fhl2 (four and a half LIM domains 2, GenBank:NM_001450), Lasp1 (LIM and SH3 protein 1, GenBank:NM_006148), Pdlim1 (PDZ and LIM domain 1 [elfin], GenBank:NM_020992), Vim (vimentin, GenBank:NM_003380), and Tubb (tubulin, $\beta$ polypeptide, GenBank:NM_001069) were quantified by real-time PCR and normalized to 18SrRNA-expression. Gene expression in IL-1 $\beta$-stimulated cells was compared with untreated cells and the effect of coincubation with SB203580 was investigated by comparison with IL-1 $\beta$-stimulated cultures. In comparison to Fhl2 and Pdim1, the expression level of Tubb was about 10-fold and of Vim, Fhl1, and Lasp1 about 100-fold higher.

\section{Influence of IL-1 $\beta$ on Gene Expression Level}

Figure 2A shows the effects of IL-1 $\beta$ on gene expression after $4 \mathrm{~h}$ and $24 \mathrm{~h}$ stimulation. All four genes containing LIM domains were downregulated by IL- $1 \beta$ stimulation. Fhl1 showed a 2.5 -fold after $4 \mathrm{~h}$ $(P=0.013)$ and a 44-fold downregulation $(P<0.0001)$ after $24 \mathrm{~h}$ of stimulation. For $F h l 2$, we found a highly significant downregulation after $4 \mathrm{~h}$ (6.5-fold, $P<0.0001)$ and $24 \mathrm{~h}$ (3.5-fold, $P<0.0001)$. Lasp1 was 2.3-fold downregulated after $4 \mathrm{~h}(P<$ $0.001)$ and 2.5-fold after $24 \mathrm{~h}(P<0.001)$ whereas Pdlim1 showed significant downregulation after $24 \mathrm{~h}(2.4$-fold, $P<0.01)$ but not after $4 \mathrm{~h}$. Tubb and Vim were downregulated after $24 \mathrm{~h}$ (3-fold and 5-fold, respectively, $P<0.0001)$. In all cases, the direction and the magnitude of the gene expression changes of the $24 \mathrm{~h}$ data were consistent with the microarray data, though, in the case of Vim, the results of the microarray failed the significance level of $P<0.05$ (array data: fold change $=0.34, P=0.077$ ).

\section{Influence of p38 MAPK Inhibition by SB203580 on Gene Expression Level}

The effect of SB203580 on gene expression in IL-1 $\beta$-stimulated cells is il- 


\section{IL-IB AND CHONDROCYTE CYTOSKELETON}

Table 2. IL-1 $\beta$-regulated, cytoskeleton-related genes found in microarray experiment The fold-change gives the ratio of expression levels comparing $24 \mathrm{~h} \mathrm{IL-1 \beta -stimulated} \mathrm{cells} \mathrm{to} \mathrm{control} \mathrm{cells.} \mathrm{The} \mathrm{most} \mathrm{strongly} \mathrm{regulated}$ genes showing $P$-values $<0.05$ are listed. Also all genes further analyzed by quantitative real-time PCR are listed and highlighted. Three independent experiments using each a pool of six donors were conducted.

\begin{tabular}{|c|c|c|c|c|}
\hline \multirow[b]{2}{*}{ Gene Symbol } & \multirow[b]{2}{*}{ Gene Description } & \multirow{2}{*}{$\begin{array}{c}\text { GenBank } \\
\text { Accession No }\end{array}$} & \multicolumn{2}{|c|}{ Influence of IL-1 $\beta$} \\
\hline & & & Fold Change & P-Value \\
\hline \multicolumn{5}{|c|}{ Downregulation } \\
\hline FHL 1 & Four and a half LIM domains 1 & NM_001449 & 0.04 & 0.001 \\
\hline ITGA 11 & Integrin, $\alpha 11$ & AF109681 & 0.09 & 0.000 \\
\hline SGCB & Sarcoglycan, $\beta$ & NM_000232 & 0.09 & 0.002 \\
\hline EMAPL & Echinoderm microtubule-assoc. protein-like & NM_004434 & 0.10 & 0.035 \\
\hline SPTA 1 & Spectrin, alpha, erythrocytic 1 & NM_003126 & 0.10 & 0.000 \\
\hline TUBB & Tubulin, $\beta$ polypeptide & NM_001069 & 0.19 & 0.000 \\
\hline SNTG 1 & Syntrophin, $\gamma 1$ & NM_018967 & 0.20 & 0.010 \\
\hline ARPC IB & Actin related protein $2 / 3$ complex & NM_005720 & 0.26 & 0.004 \\
\hline $\mathrm{FHL} 2$ & Four and a half LIM domains 2 & NM_001450 & 0.28 & 0.001 \\
\hline CALD1 & Caldesmon 1 & NM_033138 & 0.29 & 0.041 \\
\hline MYO6 & Myosin VI & NM_004999 & 0.30 & 0.036 \\
\hline CDC42BPB & CDC42 binding protein kinase $\beta$ & NM_006035 & 0.31 & 0.014 \\
\hline MYOID & Myosin ID & AKO26920 & 0.31 & 0.002 \\
\hline VIM & Vimentin & NM_003380 & 0.34 & 0.077 \\
\hline PDLIM1 & PDZ and LIM domain 1 (elfin) & NM_020992 & 0.35 & 0.025 \\
\hline ACTG1 & Actin, $\gamma 1$ & NM_001614 & 0.39 & 0.017 \\
\hline ITGB5 & Integrin, $\beta 5$ & NM_002213 & 0.41 & 0.004 \\
\hline LASP1 & LIM and SH3 protein 1 & NM_006148 & 0.41 & 0.001 \\
\hline COROIC & Coronin, actin binding protein, 1C & AL162070 & 0.41 & 0.004 \\
\hline KRT1 & Keratin 1 & NM_006121 & 0.42 & 0.036 \\
\hline LMNA & Lamin A/C & NM_005572 & 0.43 & 0.003 \\
\hline PLS3 & Plastin 3 (T isoform) & NM_005032 & 0.44 & 0.005 \\
\hline COROIA & Coronin, actin binding protein, $1 \mathrm{~A}$ & NM_007074 & 0.45 & 0.003 \\
\hline PFN2 & Profilin 2 & NM_053024 & 0.45 & 0.003 \\
\hline KRT9 & Keratin 9 & NM_000226 & 0.45 & 0.026 \\
\hline \multicolumn{5}{|l|}{ Upregulation } \\
\hline SLC9A3R1 & Solute carrier fam. 9, isoform 3 regul. factor 1 & NM_004252 & 16.83 & 0.004 \\
\hline KRTHA7 & Keratin, hair, acidic, 7 & NM_003770 & 16.81 & 0.004 \\
\hline SNTG2 & Syntrophin, $\gamma 2$ & NM_018968 & 8.30 & 0.010 \\
\hline ITGB3BP & Integrin $\beta 3$ binding protein & NM_014288 & 6.14 & 0.037 \\
\hline ITGA2B & Integrin, $\alpha 2 b$ (platelet glycoprotein llb) & NM_000419 & 4.03 & 0.001 \\
\hline SPTAN 1 & Spectrin, alpha, non-erythrocytic 1 & NM_003127 & 3.79 & 0.006 \\
\hline TEKT3 & Tektin 3 & NM_031898 & 3.22 & 0.006 \\
\hline VIL2 & Villin 2 (ezrin) & NM_003379 & 3.14 & 0.001 \\
\hline MYOIA & Myosin IA & NM_005379 & 2.83 & 0.001 \\
\hline KIF4A & Kinesin family member $4 \mathrm{~A}$ & NM_012310 & 2.74 & 0.006 \\
\hline MYO10 & Myosin $X$ & NM_012334 & 2.68 & 0.003 \\
\hline KIF3A & Kinesin family member $3 \mathrm{~A}$ & NM_007054 & 2.51 & 0.041 \\
\hline VIL 1 & Villin 1 & NM_007127 & 2.31 & 0.007 \\
\hline ITGB3 & Integrin, $\beta 3$ (platelet glycoprotein IIla) & NM_000212 & 2.27 & 0.031 \\
\hline
\end{tabular}

lustrated in Figure 2B. Fhl2 was 2.6-fold upregulated after $4 \mathrm{~h}(P<0.05)$, a tendency to upregulation also could be seen after $24 \mathrm{~h}(1.7$-fold, $P=0.07)$ and Tubb showed significant upregulation after $24 \mathrm{~h}$ (2.2-fold, $P<0.05)$. A trend of
Lasp1 upregulation was observed after 24 h (1.5-fold, $P=0.05)$. These changes were opposite to the effect of IL-1 $\beta$ stimulation without SB203580-treatment. The expression of the other IL- $1 \beta$-regulated genes (Fhl1, Pdlim1, and Vim) was not modulated by SB203580. Comparison with the microarray data showed accordance of the gene expression of Fhl1, $T u b b$, and, in tendency, of Lasp1. In contrast, the significant upregulation of Pdlim1 and Vim, as assessed in the mi- 
Table 3. SB203580-influenced, cytoskeleton-related genes found in microarray experiment The fold-change gives the ratio of expression levels comparing $24 \mathrm{~h} \mathrm{SB203580-treated} \mathrm{and} \mathrm{IL-1} \beta$-stimulated cells to IL-1 $\beta$-stimulated cells without inhibition. The most strongly regulated genes showing $P$-values $<0.05$ are listed. Also, all genes further analyzed by quantitative real-time PCR are listed and highlighted. Three independent experiments using each a pool of six donors were conducted.

\begin{tabular}{|c|c|c|c|c|}
\hline \multirow[b]{2}{*}{ Gene Symbol } & \multirow[b]{2}{*}{ Gene Description } & \multirow{2}{*}{$\begin{array}{c}\text { GenBank } \\
\text { Accession No }\end{array}$} & \multicolumn{2}{|c|}{ Influence of SB203580 } \\
\hline & & & Fold Change & P-Value \\
\hline \multicolumn{5}{|l|}{ Downregulation } \\
\hline MAPRE2 & Microtubule-associated protein, RP/EB family & NM_014268 & 0.12 & 0.005 \\
\hline bf SLC9A3R1 & Solute carrier fam. 9, isoform 3 regul. factor 1 & NM_004252 & 0.13 & 0.013 \\
\hline MAPILC3A & Microtubule-associated protein 1 light chain 3a & NM_032514 & 0.17 & 0.010 \\
\hline KRTHA7 & Keratin, hair, acidic, 7 & NM_003770 & 0.19 & 0.015 \\
\hline MAP7 & Microtubule-associated protein 7 & NM_003980 & 0.21 & 0.006 \\
\hline IQGAP2 & IQ motif containing GTPase activating prot. 2 & NM_006633 & 0.26 & 0.043 \\
\hline ITGA2B & Integrin, $\alpha 2 b$ (platelet glycoprotein IIb) & NM_000419 & 0.32 & 0.027 \\
\hline KRTHB6 & Keratin, hair, basic, 6 (monilethrix) & NM_002284 & 0.41 & 0.007 \\
\hline DOCK 1 & Dedicator of cyto-kinesis 1 & NM_001380 & 0.42 & 0.010 \\
\hline EPB41 & Erythrocyte membrane protein band 4.1 & NM_004437 & 0.42 & 0.044 \\
\hline CYLC2 & Cylicin 2 & NM_001340 & 0.43 & 0.020 \\
\hline KRT7 & Keratin 7 & NM_005556 & 0.45 & 0.010 \\
\hline FNI & Fibronectin 1 & NM_002026 & 0.45 & 0.03 \\
\hline MLFl & Myeloid leukemia factor 1 & NM_022443 & 0.48 & 0.027 \\
\hline FHL 1 & Four and a half LIM domains 1 & NM_001449 & 0.84 & 0.756 \\
\hline \multicolumn{5}{|l|}{ Upregulation } \\
\hline HARP1 1 & Hypothalamus protein HARP1 1 & NM_018477 & 12.76 & 0.021 \\
\hline EMAPL & Echinoderm microtubule-assoc. protein-like & NM_004434 & 10.52 & 0.020 \\
\hline SGCB & Sarcoglycan, $\beta$ & NM_000232 & 6.32 & 0.009 \\
\hline CDC42BPB & CDC42 binding protein kinase $\beta$ & NM_006035 & 6.25 & 0.005 \\
\hline SGCG & Sarcoglycan, $\gamma$ & NM_000231 & 6.22 & 0.011 \\
\hline NF2 & Neurofibromin 2 (bilateral acoustic neuroma) & AF369658 & 5.19 & 0.007 \\
\hline HINT & Histidine triad nucleotide binding protein & AK054976 & 4.24 & 0.034 \\
\hline VIM & Vimentin & NM_003380 & 3.77 & 0.001 \\
\hline PKP3 & Plakophilin 3 & NM_007183 & 3.59 & 0.010 \\
\hline KNSL5 & Kinesin-like 5 (mitotic kinesin-like protein 1) & NM_004856 & 3.56 & 0.015 \\
\hline TUBB & Tubulin, $\beta$ polypeptide & NM_001069 & 3.21 & 0.014 \\
\hline ACTL7A & Actin-like 7A & NM_006687 & 2.82 & 0.030 \\
\hline RNF28 & Ring finger protein 28 & AF361946 & 2.55 & 0.007 \\
\hline LASP1 & LIM and SH3 protein 1 & NM_006148 & 2.33 & 0.018 \\
\hline MARKL 1 & MAP/microtubule affinity-regul. kinase like 1 & $\mathrm{AB} 058763$ & 2.32 & 0.022 \\
\hline ITGB3BP & Integrin $\beta 3$ binding protein & NM_014288 & 2.26 & 0.020 \\
\hline PDLIM1 & PDZ and LIM domain 1 (elfin) & NM_020992 & 2.23 & 0.028 \\
\hline $\mathrm{FHL2}$ & Four and a half LIM domains 2 & NM_001450 & 1.23 & 0.773 \\
\hline
\end{tabular}

croarray, could not be confirmed in realtime PCR.

\section{Changes in Morphology and Cytoskeletal Organization of Chondrocytes by IL- $1 \beta$}

Figure 3 visualizes the effects of IL-1 $\beta$ on the cell morphology of chondrocytes. Control cells showed a flattened shape (A). Phalloidin staining indicated good adherence on the surface by focal adhesion sites and a meshwork of actin fila- ments with stress fibers (C). Compared with control cells, IL-1 $\beta$-stimulated chondrocytes presented a completely different appearance. After $24 \mathrm{~h}$, many cells had begun to shrink $(B, D)$ and showed a spherical shape. No cytoskeletal structure could be observed in the spherical cells by phalloidin staining. Pretreatment with SB203580 could not prevent the morphological changes seen in IL-1 $\beta$-stimulated cells (data not shown).

\section{Regulation of FHL2 Protein Expression and Distribution}

According to gene expression data, Western blot analysis (Figure 4A) confirmed downregulation of FHL2 by IL-1 $\beta$ on protein level. The rating of band intensity revealed a significant influence after $48 \mathrm{~h}$ of stimulation. Preincubation with SB203580 could not diminish this effect markedly. In addition, specific immunoreactivity could be observed for a 23 kDa Peptide, probably a proteolytic 

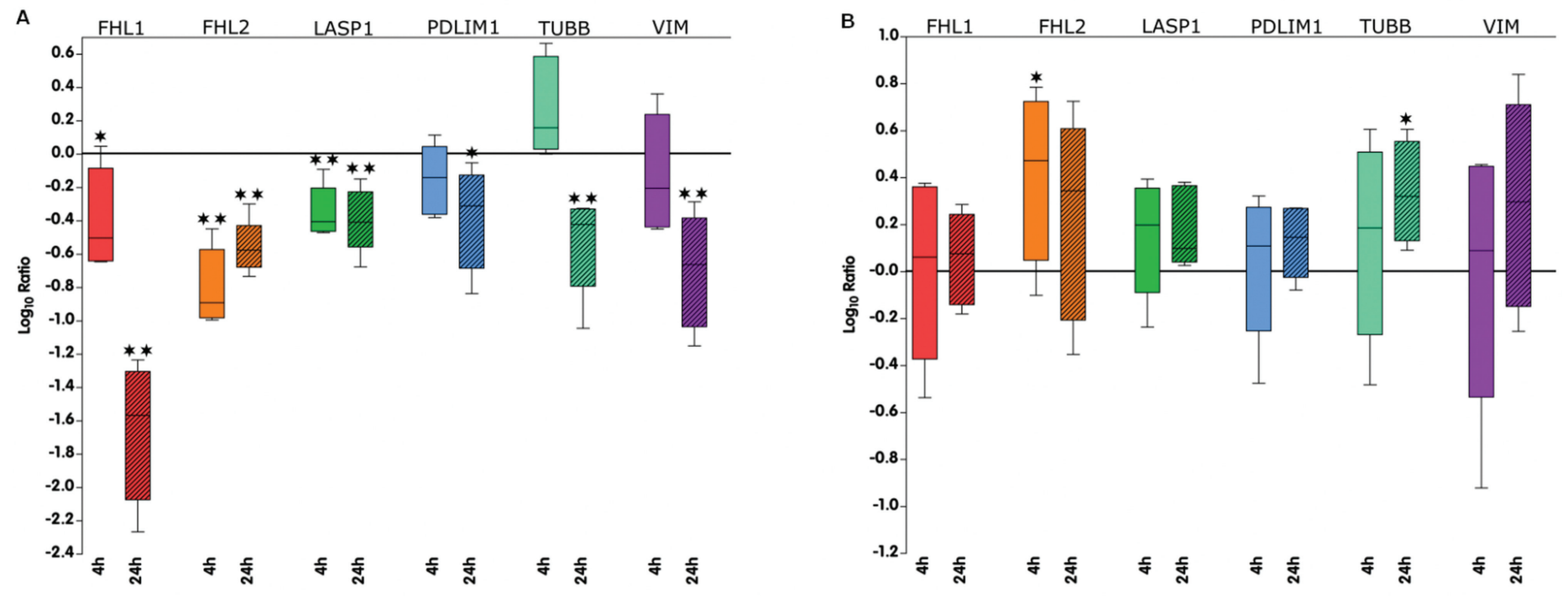

Figure 2. Influence of cell treatment on gene expression. Quantitative real-time PCR analysis for levels of mRNA expression of cytoskeletonrelated genes in IL-1 $\beta$-stimulated chondrocytes. Values are the $\log _{10}$-ratios of A: IL-1 $\beta$ stimulated to control gene expression levels and B: P38 MAPK-inhibited and IL-1 $\beta$ stimulated to IL-1 $\beta$ stimulated gene expression levels without inhibition. Six donors were analyzed. The stimulation times of $4 \mathrm{~h}$ and $24 \mathrm{~h}$, respectively, are indicated. Significant changes are marked (*: $\left.P<0.05,{ }^{* *}: P<0.001\right)$.
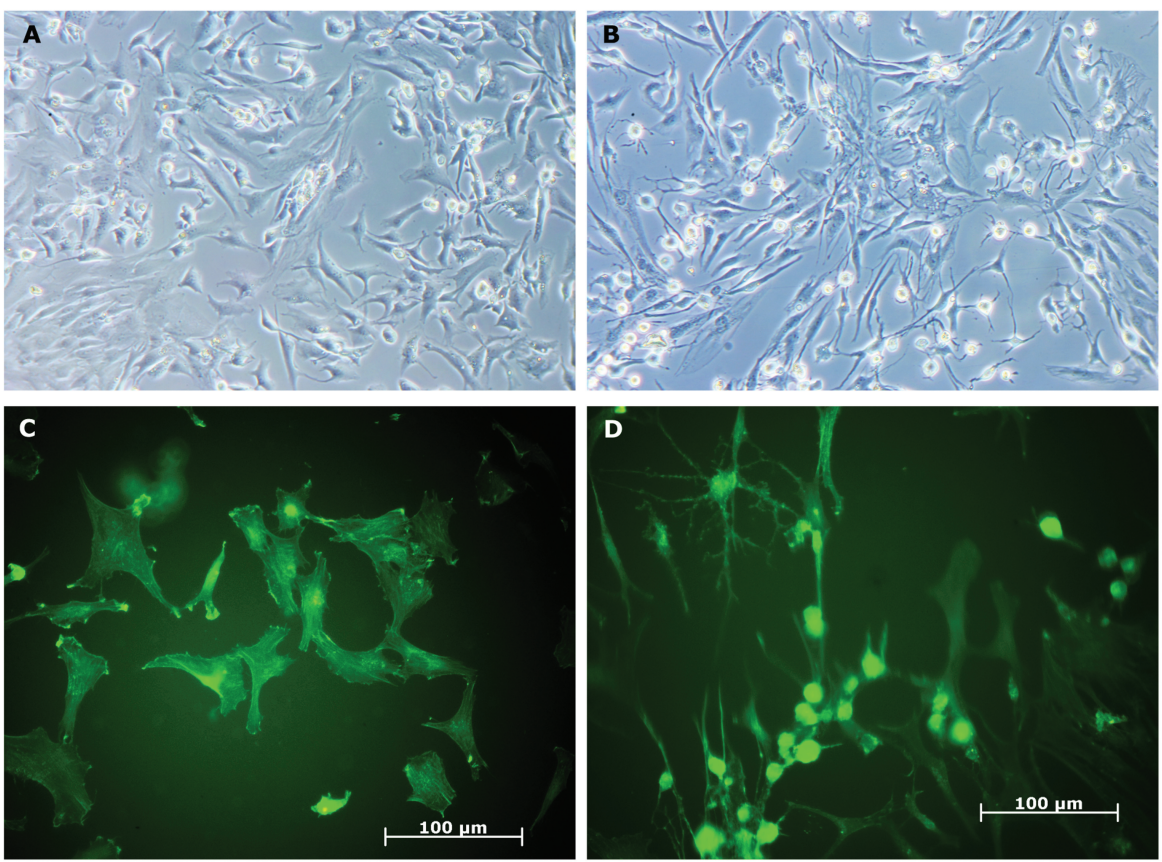

Figure 3. Influence of IL-1 $\beta$ on cell morphology. Chondrocytes with $(B, D)$ and without (A, C) $24 \mathrm{~h} / \mathrm{L}-1 \beta$ stimulation ( $10 \mathrm{ng} / \mathrm{mL}$ ). A + B: Phase contrast microscopy of chondrocytes grown on cell culture dishes (magnification 200x). C + D: Fluorescence microscopy of chondrocytes grown on Permanox slides and F-actin-stained with FITC-conjugated phalloidin. fragment (27), that was upregulated by stimulation with IL-1 $\beta$ (data not shown). FHL2 immunostaining of untreated cells (Figure 4B) showed a typical localization of the protein at sites of adhesion, but also in and round the nucleus. IL- $1 \beta$ treatment mostly disturbed the flattened morphology and the described FHL2 distribution. Stimulated chondrocytes revealed a uniformly distributed strong staining in rounded cells, but diminished localization in focal adhesion sites in cells that still showed a flattened shape (Figure 4C).

\section{DISCUSSION}

By using a microarray approach in primary human osteoarthritic chondrocytes, we were able to identify a large group of cytoskeleton-related genes that showed changes in gene expression in response to IL-1 $\beta$ treatment. In real-time PCR analysis, we confirmed significant downregulation of four genes containing LIM domains and of Tubb and Vim gene expression by IL-1 $\beta$ treatment in good 
A



B



Figure 4. Influence of IL-1 $\beta$ on FHL2 protein expression and distribution. A: Western blot analysis from treated and untreated chondrocytes and corresponding analysis of band intensity of four (IL-1 $\beta$ treatment) and two (SB203580 and IL-1 $\beta$ treatment) independent experiments, respectively. B + C: Chondrocytes with (C) and without (B) IL-1 $\beta$ stimulation stained with $\alpha \mathrm{FHL} 2$ antibody.

accordance to the microarray results. Both expression and regulation of the LIM protein related genes as well as regulation of Tubb and Vim by IL-1 $\beta$ are new aspects in cartilage research. The inhibition of p38 MAPK with SB203580 could significantly counteract the influence of IL-1 $\beta$ on Fhl2 and Tubb expression, indicating an involvement of the p38 MAPK pathway in these cases. Corresponding to these results in gene expression analyses, we have demonstrated IL-1 $\beta$ regulation of FHL2 protein expression and effects on cell morphology and the distribution of FHL2 and the actin cytoskeleton of cultured chondrocytes. Therefore, we suggest an influence of IL-1 $\beta$ on the cytoskeletal organization of chondrocytes. A closer look at the biological functions of the proteins associated with the analyzed genes supports this notion.

FHL2 is a member of the four-and-ahalf LIM family, that consists of five different proteins (17). It can interact with more than 50 different proteins including transcription factors, integrins, or structural cytoskeletal proteins such as actin. FHL2 lacks an obvious enzymatic activity, but a function as a scaffolding protein providing docking sites for other proteins was suggested (27). Its localization at adhesion complexes and in the nucleus observed in this work was also described for mouse fibroblasts (28). These findings support a role for this LIM protein as a signal transducer (27). It was shown that FHL2 acts as a molecular transmitter of the Rho signaling pathway, which is involved in the organization of the actin cytoskeleton (28). Moreover, FHL2 interacts with RUNX2, a transcriptional regulator not only involved in osteogenesis, but also in chondrogenesis. RUNX2 contributes to MMP13 expression (29) and is induced in early osteoarthritis (30). This may support the notion that FHL2 is involved not only in cytoskeletal changes but also in OA-associated transcriptional regulation in IL-1 $\beta$-stimulated chondrocytes. The regulation of the Fhl2 expression is un- derstood only partially. Transcription of Fhl2 is induced by serum (31), which can be seen as a model for anabolic processes. By contrast, IL-1 $\beta$ stimulation as a model for catabolic processes in chondrocytes (6) downregulated FHL2 gene and protein expression, as shown in this paper. Our finding that inhibition of the p38 MAPK diminishes the effect of IL-1 $\beta$ on Fhl2 gene expression suggests at least partial regulation of Fhl2 transcription via the p38 MAPK pathway. Indeed, there is a binding site for the p38 MAPKregulated transcription factor MEF-2 in the Fhl2 promoter $(27,32)$. Because this effect could not be confirmed significantly on the protein level, further regulatory mechanisms on posttranscriptional level might be involved. Another reason could be the semiquantitative method of Western blot analysis that might not be sensitive enough to detect small changes on the protein level.

The other cytoskeleton associated LIM proteins FHL1, LASP1 and PDLIM1 also are associated with the actin cytoskeleton (33). Their specific roles are poorly understood, but they are suggested to fulfill functions in signal transduction. This is the first description of their expression and regulation in chondrocytes. FHL1, another member of the four-and-a-half LIM family, shows an integrin-dependent localization at focal adhesions, stress fibers, and the nucleus in myoblasts. It regulates integrin-mediated cellular functions such as cytoskeletal rearrangement, probably by regulating transcription factors (34). The LASP1 protein includes two actin binding sites and an $\mathrm{SH}_{3}$ domain which is involved in binding to special focal adhesion proteins like zyxin and VASP. These binding properties make LASP1 a candidate for a scaffold protein that mediates formation of protein complexes. Stimulation with growth factors or ECM proteins facilitates its localization to focal complexes and actin polymerization sites, whereas the loss of LASP1 localization to FACs is associated with the induction of cell death (35). PDLIM1 belongs to the Enigma family and contains 1 PDZ and 1 
LIM domain. It colocalizes with $\alpha$-actinin and actin stress fibers in different cell types and may modulate the function of $\alpha$-actinin 1 (36). Presuming comparable functions in chondrocytes, the downregulation of these LIM protein related genes may interfere with cytoskeletal arrangements and affect associated signaling pathways. The resulting total effect of IL-1 $\beta$ on actin polymerization and focal complex formation also may influence cell motility. There are some reports indicating the capacity of chondrocytes to migrate in vitro (37). This feature of chondrocytes also was addressed by new approaches for cartilage repair in vivo (38). An affection of cell migration by NO via the disruption of ECM adherence and actin assembly has been described for chondrocytes and an impairment of cartilage repair was suspected as a consequence (39).

Tubulin and Vimentin, components of microtubules and intermediate filaments, respectively, play major roles in intracytoplasmic transport and cell stability. The disruption of these structures in chondrocytes diminishes collagen type II-synthesis and, in case of tubulin, the synthesis of proteoglycans. It could promote an imbalance in cartilage homeostasis due to reduced anabolism (10). Disrupted intermediate filaments alter the viscoelastic properties of chondrocytes which might be associated to the increased cellular stiffness observed in OA cartilage (9). It has been shown that the number of tubulin- and vimentinpositive chondrocytes is significantly reduced in rat OA cartilage in comparison to normal cartilage (40). Accordingly, changes in cell morphology have been described in human OA chondrocytes in vivo, including disruption of the cytoskeleton. Especially the clustered cells from the upper zone cartilage displayed a disrupted distribution of actin, vimentin, and tubulin (7). The cells in the upper zone of articular cartilage are exposed mainly to inflammatory cytokines like IL-1 $\beta$. These results agree with our new finding, that IL-1 $\beta$ significantly downregulates Tubb and Vim gene ex- pression in chondrocytes and affects chondrocyte morphology in vitro.

The effects of IL- $1 \beta$ on various cytoskeletal components may be involved directly in OA pathogenesis as they could have complex effects on signal transduction to the nucleus, on anabolic and catabolic pathways, on viscoelastic properties, on cell motility, and on the responsiveness to extracellular stimuli. A deeper knowledge of the involved molecular processes also may help to set different pathogenetic mechanisms of degenerative joint diseases in a novel context.

\section{ACKNOWLEDGMENTS}

The authors would like to thank ratiopharm Ulm for supporting this study and providing SB203580, Dr. Wixler, Münster, for the FHL2-Antibody and Dr. Holzmann from the Microarray-Facility Ulm for his support in the chip analysis.

\section{REFERENCES}

1. Sandell LJ, Aigner T. (2001) Articular cartilage and changes in arthritis. An introduction: cell biology of osteoarthritis. Arthritis Res. 3:107-13.

2. Aida $Y$, Maeno M, Suzuki N, Shiratsuchi $H$, Motohashi M, Matsumura H. (2005) The effect of IL-1beta on the expression of matrix metalloproteinases and tissue inhibitors of matrix metalloproteinases in human chondrocytes. Life Sciences. 77:3210-21.

3. Demircan K, Hirohata S, Nishida K, Hatipoglu OF, Oohashi T, Yonezawa T, Apte SS, Ninomiya Y. (2005) ADAMTS-9 is synergistically induced by interleukin-1beta and tumor necrosis factor alpha in OUMS-27 chondrosarcoma cells and in human chondrocytes. Arthritis Rheum. 52:1451-60.

4. Goldring MB, Birkhead J, Sandell LJ, Kimura T, Krane SM. (1988) Interleukin 1 suppresses expression of cartilage-specific types II and IX collagens and increases types I and III collagens in human chondrocytes. J. Clin. Invest. 82:2026-37.

5. Stove J, Huch K, Gunther KP, Scharf HP. (2000) Interleukin-1beta induces different gene expression of stromelysin, aggrecan and tumor-necrosisfactor-stimulated gene 6 in human osteoarthritic chondrocytes in vitro. Pathobiology. 68:144-9.

6. Aigner T, McKenna L, Zien A, Fan Z, Gebhard PM, Zimmer R. (2005) Gene expression profiling of serum- and interleukin-1 beta-stimulated primary human adult articular chondrocytes-a molecular analysis based on chondrocytes isolated from one donor. Cytokine. 31:227-40.

7. Kouri JB, Lavalle C. (2006) Do chondrocytes undergo "activation" and "transdifferentiation" during the pathogenesis of osteoarthritis? A re- view of the ultrastructural and immunohistochemical evidence. Histol. Histopathol. 21:793-802.

8. Kouri JB, Arguello C, Luna J, Mena R. (1998) Use of microscopical techniques in the study of human chondrocytes from osteoarthritic cartilage: an overview. Microsc. Res. Tech. 40:22-36.

9. Trickey WR, Vail TP, Guilak F. (2004) The role of the cytoskeleton in the viscoelastic properties of human articular chondrocytes. J. Orthop. Res. 22:131-9.

10. Blain EJ, Gilbert SJ, Hayes AJ, Duance VC. (2006) Disassembly of the vimentin cytoskeleton disrupts articular cartilage chondrocyte homeostasis. Matrix Biology. 25:398-408.

11. Kim S-J, Hwang S-G, Kim I-C, Chun J-S. (2003) Actin cytoskeletal architecture regulates nitric oxide-induced apoptosis, dedifferentiation, and cyclooxygenase- 2 expression in articular chondrocytes via mitogen-activated protein kinase and protein kinase C pathways. J. Biol. Chem. 278:42448-56.

12. Lombardi A, Pignone A, Perfetto F, Tarquini R, Partsch G, Matucci-Cerinic M. (1993) The enzymatic mechanisms involved in the pathogenesis of rheumatoid arthritis and arthrosis. The role of metalloproteases and serine proteases in the breakdown of articular cartilage. Recenti. Prog. Med. 84:634-41.

13. MacGillivray MK, Cruz TF, McCulloch CA. (2000) The recruitment of the interleukin-1 (IL-1) receptorassociated kinase (IRAK) into focal adhesion complexes is required for IL-1beta -induced ERK activation. J. Biol. Chem. 275:23509-15.

14. Mendes AF, Caramona MM, Carvalho AP, Lopes MC. (2002) Role of mitogen-activated protein kinases and tyrosine kinases on IL-1-Induced NFkappaB activation and iNOS expression in bovine articular chondrocytes. Nitric Oxide. 6:35-44.

15. Radons J, Bosserhoff AK, Graessel S, Falk W, Schubert TEO. (2006) p38MAPK mediates IL-1induced downregulation of aggrecan gene expression in human chondrocytes. Int. J. Mol. Med. 17:661-8.

16. Bach I. (2000) The LIM domain: regulation by association. Mech. Dev. 91:5-17.

17. Khurana T, Khurana B, Noegel AA. (2002) LIM proteins: association with the actin cytoskeleton. Protoplasma. 219:1-12.

18. Mankin HJ, Dorfman H, Lippiello L, Zarins A. (1971) Biochemical and metabolic abnormalities in articular cartilage from osteo-arthritic human hips, II. Correlation of morphology with biochemical and metabolic data. Journal of Bone and Joint Surgery. 53:523-37.

19. Buchholz M, Braun M, Heidenblut A, Kestler HA, Kloeppel G, Schmiegel W, Hahn SA, Luettges J, Gress TM. (2005) Transcriptome analysis of microdissected pancreatic intraepithelial neoplastic lesions. Oncogene. 24:6626-36.

20. Kendziorski C, Irizarry RA, Chen KS, Haag JD, Gould MN. (2005) On the utility of pooling biological samples in microarray experiments. Proc. Natl. Acad. Sci. U. S. A. 102:4252-7. 
21. Babelomics-Tools. In: http://www.babelomics.org/.

22. Al-Shahrour F, Minguez P, Tarraga J, Montaner D, Alloza E, Vaquerizas JM, Conde L, Blaschke C, Vera J, Dopazo J. (2006) BABELOMICS: a systems biology perspective in the functional annotation of genome-scale experiments. Nucleic Acids Res. 34(Web Server issue):W472-6.

23. Primer 3. In: http://frodo.wi.mit.edu/cgi-bin/primer3/ primer3_www.cgi.

24. Smyth GK. (2004) Linear models and empirical Bayes methods for assessing differential expression in microarray experiments. Stat. Appl. Genet. Mol. Biol. 3:Article3. Epub 2004 Feb 12.

25. Mengshol JA, Vincenti MP, Brinckerhoff CE. (2001) IL-1 induces collagenase-3 (MMP-13) promoter activity in stably transfected chondrocytic cells: requirement for Runx-2 and activation by p38 MAPK and JNK pathways. Nucleic Acids Res. 29:4361-72.

26. Nieminen R, Leinonen S, Lahti A, Vuolteenaho K, Jalonen U, Kankaanranta H, Goldring MB, Moilanen E. (2005) Inhibitors of mitogenactivated protein kinases downregulate COX-2 expression in human chondrocytes. Mediators Inflamm. 2005:249-55.

27. Johannessen M, Moller S, Hansen T, Moens U, Ghelue MV. (2006) The multifunctional roles of the four-and-a-half-LIM only protein FHL2. Cell Mol. Life Sci. 63:268-84.

28. Mueller JM, Metzger E, Greschik H, Bosserhoff A-K, Mercep L, Buettner R, Schuele R. (2002) The transcriptional coactivator FHL2 transmits Rho signals from the cell membrane into the nucleus. EMBO. J. 21:736-48.

29. Wang X, Manner PA, Horner A, Shum L, Tuan RS, Nuckolls GH. (2004) Regulation of MMP-13 expression by RUNX2 and FGF2 in osteoarthritic cartilage. Osteoarthritis Cartilage. 12:963-73.

30. Kamekura S et al. (2006) Contribution of runtrelated transcription factor 2 to the pathogenesis of osteoarthritis in mice after induction of knee joint instability. Arthritis Rheum. 54:2462-70.

31. Morlon A, Sassone-Corsi P. (2003) The LIM-only protein FHL2 is a serum-inducible transcriptional coactivator of AP-1. Proc. Natl. Acad. Sci. U. S. A. 100:3977-82.

32. Han J, Molkentin JD.(2000) Regulation of MEF2 by 338 MAPK and its implication in cardiomyocyte biology. Trends Cardiovasc. Med. 10:19-22.

33. Dawid IB, Breen JJ, Toyama R. (1998) LIM domains: multiple roles as adapters and functional modifiers in protein interactions. Trends Genet. 14:156-62.

34. Robinson PA, Brown S, McGrath MJ, Coghill ID, Gurung R, Mitchell CA. (2003) Skeletal muscle LIM protein 1 regulates integrin-mediated myoblast adhesion, spreading, and migration. Am. J. Physiol. Cell Physiol. 284:C681-95.

35. Lin YH, Park Z-Y, Lin D, Brahmbhatt AA, Rio MC, Yates JR, Klemke RL. (2004) Regulation of cell migration and survival by focal adhesion targeting of Lasp-1. J. Cell Biol. 2004, 165:421-32.

36. Bauer K, Kratzer M, Otte M, de Quintana KL, Hagmann J, Arnold GJ, Eckerskorn C, Lottspeich
F, Siess W. (2000) Human CLP36, a PDZ-domain and LIM-domain protein, binds to alpha-actinin1 and associates with actin filaments and stress fibers in activated platelets and endothelial cells. Blood. 96:4236-45.

37. Morales TI. (2007) Chondrocyte moves: clever strategies? Osteoarthritis Cartilage. 15:861-71.

38. Lu Y, Dhanaraj S, Wang Z, Bradley DM, Bowman SM, Cole BJ, Binette F. (2006) Minced cartilage without cell culture serves as an effective intraoperative cell source for cartilage repair. J. Orthop. Res. 24:1261-70.

39. Frenkel SR, Clancy RM, Ricci JL, Di Cesare PE, Rediske JJ, Abramson SB. (1996) Effects of nitric oxide on chondrocyte migration, adhesion, and cytoskeletal assembly. Arthritis Rheum. 39:1905-12.

40. Capin-Gutierrez N, Talamas-Rohana P, GonzalezRobles A, Lavalle-Montalvo C, Kouri JB. (2004) Cytoskeleton disruption in chondrocytes from a rat osteoarthrosic (OA) -induced model: its potential role in OA pathogenesis. Histol. Histopathol. 19:1125-32. 